\title{
NOTAS DE AQUÍ . . .
}

\section{Hacia un Cambio en los Procesos DE Acción Social Colombianos}

\author{
Por: Mary Berrio Berrio \\ Indira Joly Geliz
}

Artículo Recibido: Octubre 24 de 2007

Artículo Aceptado: Marzo 27 de 2008

\section{RESUMEN}

Este texto presenta una reflexión crítica sobre la acción social en Colombia haciendo referencia a la perspectiva con las que ONG's gubernamentales y no gubernamentales manejan el apoyo social a las poblaciones vulnerables y la ausencia en ellas de un propósito de construir ciudadanos capaces de participar en el cambio social.

Palabras Claves: Procesos sociales, acción social, trabajo social.

\section{Introducción}

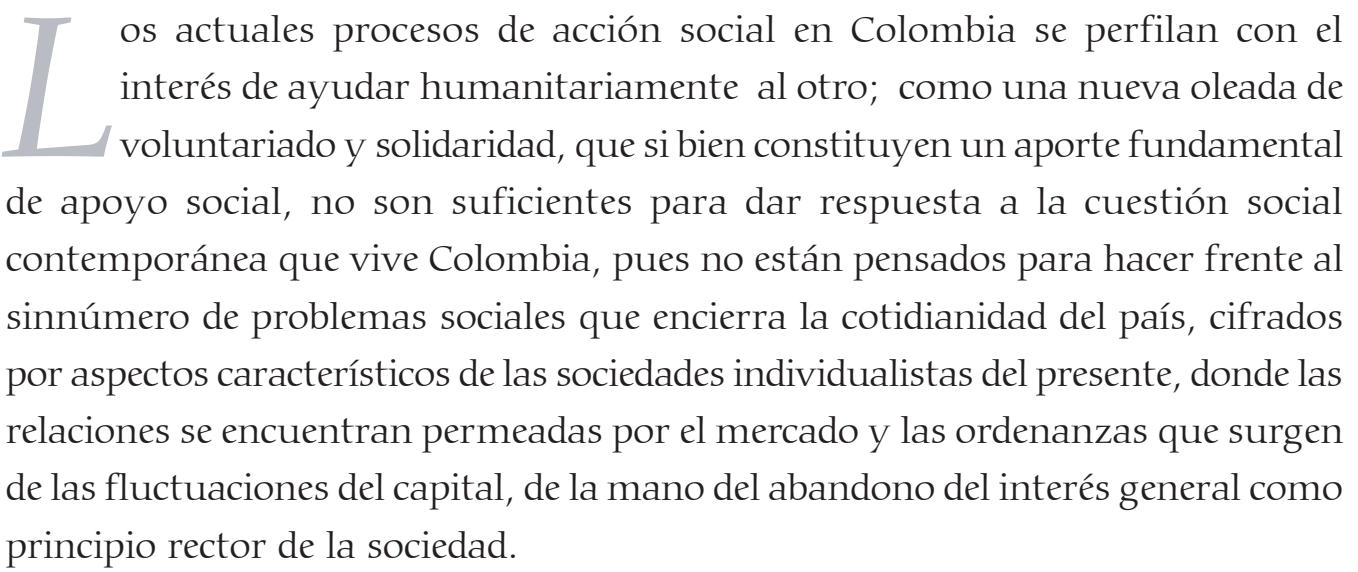

Considerando las demandas actuales de la sociedad, donde predomina, como señala Gino Germani, ${ }^{1}$ la autonomía individual y la propiedad privada, y

\footnotetext{
Marturet, Hernán Javier. (2002). Visiones abiertas y cerradas de la modernidad. Una lectura de Gilles Lipovetky y Alain Tourraine. Universidad libros. Buenos Aires, pág. 10.
} 
2 Se dice "algunos" para resaltar que en si misma estadenotación de vulnerable $y$ necesitado genera marginación social, al considerarlos incapacitados para participar en las relaciones que imperan en la organización social de la Colombia actual.

3 http//www. un.org/spanish/ milleniumgoals /$33 \mathrm{k}$. en donde las relaciones se encuentran transversalizadas por las exigencias del mercado y los requerimientos del capital, que como señaló Durkheim, lleva a que los individuos se muevan de acuerdo a lo que el sistema social y económico les impone. Basado en esto, se entiende que las personas y las instituciones sociales han de organizarse a la luz de los cambios y permanencias dadas en sus contextos para sobrevivir en los mismos, por lo que las estrategias de acción social impulsadas en el caso de este país, deben partir de un análisis de las situaciones del contexto y de la intencionalidad de vincular a los ciudadanos en los procesos que estás traen consigo.

\section{Críticas a las Formas de Acción Social en Colombia}

Se hace necesaria una reformulación de los procesos de acción social mediante la contemplación de los individuos como ciudadanos, no sólo como sujetos de derechos sino también de deberes, a fin de promover inclusión social, a través de la creación de oportunidades y la generación de capacitación a los potenciales agentes del cambio.

En este sentido se debe señalar que las estrategias de intervención fruto de las preocupaciones por los sectores de población pobres y vulnerables, organizadas en el seno de lo público (Instituciones Gubernamentales) y de la sociedad civil o iniciativa privada, a través de las llamadas Organizaciones no Gubernamentales, se han traducido en muchos casos en paliativos, que aunque muestran un sentido ampliamente solidario, no son suficientes para erradicar la miseria que invade crecientemente las calles y los hogares de este país.

Para sustentar lo dicho, se pretende plantear unos elementos críticos a las formas de acción social que se trabajan hoy día desde el ámbito de lo público (Organizaciones Gubernamentales) y desde las Organizaciones No Gubernamentales a nivel nacional; y a partir de ello enunciar algunos aspectos a tener en cuenta para la formulación de propuestas estratégicas para la construcción de un cambio social, sobre la base de que las transformaciones sociales emprendidas por los agentes sociales (como los llamaría Anthony Giddens), deben generar un efecto positivo en el contexto nacional.

En este orden de ideas, las múltiples líneas de acción social que caracterizan la intervención pública y privada en pro del fortalecimiento de los sectores vulnerables de la población y la superación de las ínfimas condiciones de vida de algunos colombianos ${ }^{2}$ son a modo general, como dice Carlos Osorio Torres, ${ }^{3}$ 
respuestas al llamado mundial de la acción contra la pobreza, materializado en los objetivos de desarrollo del milenio. ${ }^{4}$

Para este análisis se hará referencia al caso de dos (2) de los objetivos del milenio como son: erradicar la pobreza extrema y el hambre y lograr la enseñanza primaria universal, pero también a la forma el ámbito gubernamental y no gubernamental atienden estas necesidades (alimentación y educación).

En lo que concierne a estos temas en el ámbito gubernamental, la Presidencia de la República de Colombia guía su accionar con los lineamientos que propone la Agencia Presidencial para la Acción Social y la Cooperación internacional; ${ }^{5}$ entidad creada por el gobierno nacional con el fin de canalizar los recursos nacionales e internacionales para ejecutar los programas sociales que de ella dependen (Presidencia) y que atienden a poblaciones vulnerables, afectadas por la pobreza, la violencia y el narcotráfico, a través de los programas de Familias en acción, Familias guardabosques, Proyectos productivos, Infraestructura social y Reconversión sociolaboral.

Las Organizaciones Gubernamentales procuran alcanzar los fines del Plan Nacional Estado Comunitario Desarrollo para todos (2006-2010), a cuyos propósitos están estrechamente ligadas las estrategias rectoras de los planes de desarrollo regionales y locales, y por ende, las acciones corresponden a los esfuerzos de todos, trabajando de la mano en la búsqueda de un mismo objetivo: ayudar a los pobres y mejorar la calidad de vida en la nación.

Sin embargo, "no todo lo que brilla es oro", o por lo menos no se ha encontrado la piedra filosofal; porque los programas de acción social del gobierno nacional antes mencionados se reducen a ayudas financieras y en especie, que en términos generales, podría decirse, son insuficientes para la satisfacción plena de las necesidades básicas.

Por ejemplo, un subsidio bimestral de \$ 93.000 pesos para nutrición, \$28.000 pesos para educación primaria y $\$ 56.000$ pesos para educación secundaria, que es lo que proporciona el Programa Familias En Acción, ${ }^{6}$ no alcanza a cubrir las necesidades enunciadas (educación primaria, educación secundaria y alimentación) en dos meses. Por otro lado, se trabaja con la concepción del "menor de edad", como un sujeto incapaz de acceder a servicios y satisfactores de manera autónoma e independiente, imaginario que en sí mismo es expresión de exclusión social e imposibilita la ejecución de una acción social con miras a la construcción de ciudadanía desde la niñez.

${ }^{4}$ Erradicar la pobreza extrema y el hambre, 2. Lograr la enseñanza primaria universal, 3. Promover la equidad de genero y la autonomía de la mujer, 4. Reducir la mortalidad infantil, 5. Mejorar la salud materna, 6 . Combatir el VIH/ SIDA, el paludismo y otras enfermedades, 7. Organizar la sostenibilid a d ambiental y 8 . Fomentar una asociación mundial para el desarrollo.

${ }^{5}$ Agencia Presidencial para la Acción Social y la Cooperación internacional. www. red.gov.co.

${ }^{6}$ Ibíd. 
De otra parte, las Organizaciones no Gubernamentales, actúan por iniciativa privada, particular y sin ánimo de lucro, en aras de proporcionar ayuda institucional a sectores necesitados. De esta manera, independientemente de sus campos y niveles de intervención, su esencia se constituye en un proveer constante de satisfactores de necesidades, por lo cual no se alcanza a trabajar en su totalidad la potenciación del capital humano. Salvo excepciones dignas de admiración, no se ha generado ni desarrollo sostenible en el tiempo, sino que ha sido necesaria la supervisión de los agentes que lo facilitan, como tampoco el impacto necesario para apuntar a la lucha contra la miseria (como ya se había enunciado, pues también guían su accionar a la búsqueda de los objetivos del milenio), por cuanto no se ha despertado el entusiasmo de la "materia prima" ó personas con que se cuenta, en las diversas colectividades a intervenir.

A lo anterior, se suma el hecho de que la intencionalidad está direccionada y contempla como centro de intervención a las poblaciones vulnerables, entre más vulnerables más urgente su atención, lo que ha posibilitado el robustecimiento de una "cultura de la miseria", que no da paso al incremento de la calidad de vida e imposibilita la promoción, la movilidad social. A ello se agrega la circunstancia de que la priorización de los sectores necesitados se haga mediante el uso de indicadores tangibles, a fin de focalizar los ámbitos y sujetos de intervención, lo que hace que ésta sea una estrategia ineficiente para promover un cambio real, pues el que algunas personas cuenten con un poco más de condiciones materiales para vivir que otros, no indica que cuenten con una calidad de vida que les permita satisfacer enteramente sus necesidades básicas.

\section{Nuevas Perspectivas para la Acción Social en Colombia}

Luego de un primer acercamiento a las formas de acción social en Colombia y de plantear brevemente lo que se piensa de las mismas, así como de intentar medir a modo subjetivo (desde una consideración particular, lo que no quiere decir que no sea acertada) su efectividad y partiendo de la convicción de que en Colombia se cuenta con el factor más importante, que es el interés de ayudar y el firme propósito para erradicar la pobreza y la vulnerabilidad, se considera pertinente concretar los aspectos que deben ser tenidos en cuenta para la formulación de propuestas de cambio social.

Se cree que más allá de la desinteresada u obligatoria solidaridad, es menester que los diversos grupos e instituciones que promueven la acción social en la Colombia actual, procuren la erradicación de la pobreza partiendo de la comprensión de que los sectores vulnerables (desplazados, indigentes, desempleados, entre otros marginados del orden presente, a causa de la violencia y las precarias condiciones de vida), pueden 
ser visibilizados y tratados como potenciadores de cambio y construcción, y no simplemente, como meros sectores de población carentes de recursos, inhabilitados para la solución de sus problemáticas y necesitados de la "lástima" y colaboración humana.

Así las cosas es imperativo impulsar acciones sociales con miras a la potencialización de un individuo capaz de enfrentar y superar aquellas situaciones que le vulneran, haciendo uso de los recursos que el Estado y las ONG's le ofrezcan, pero no con el propósito de depender de éstos, sino de que le ayuden a construir un desarrollo permanente en el tiempo, pese a que los recursos sean escasos.

Es necesario tratar a los diversos actores colombianos, como protagonistas de la marginación de las relaciones sociales, determinadas como ya se dijo por el mercado y la lógica individualista. Lo que se aspira lograr con la participación de las poblaciones en las que se interviene, es otorgarle a la acción, el sentido de que para superar los niveles de vida del ahora y alcanzar los deseados en el futuro, se requiere de la puesta en marcha de compromisos personales con las acciones implementadas para el alcance del bienestar general.

Por ende, lo primordial en los procesos de intervención, sin importar el ámbito, público o privado, que los promueva, debe ser la consideración de un ciudadano como sujeto de derechos. Sobre la base de esta percepción de los sujetos podrá posibilitarse un estado de cosas, en donde prime, más que el asegurar el acceso gratuito a los servicios como lo sugiere el Estado benefactor, el contribuir de manera más importante a la igualdad de oportunidades en el acceso a los servicios sociales y a la construcción de una ciudadanía activa, motivada para trabajar en pro de su inclusión en unas relaciones sociales, que han sido determinadas por los mandatos económicos y los sentidos individualistas, que paulatinamente han dejado atrás el interés general, dando paso a situaciones en el país, como la violencia, la seguridad social precaria, la crisis de identidad y el abandono de la ciudadanía, entre otros.

Para terminar, es importante también mencionar la necesidad de descentralizar el asistencialismo de las

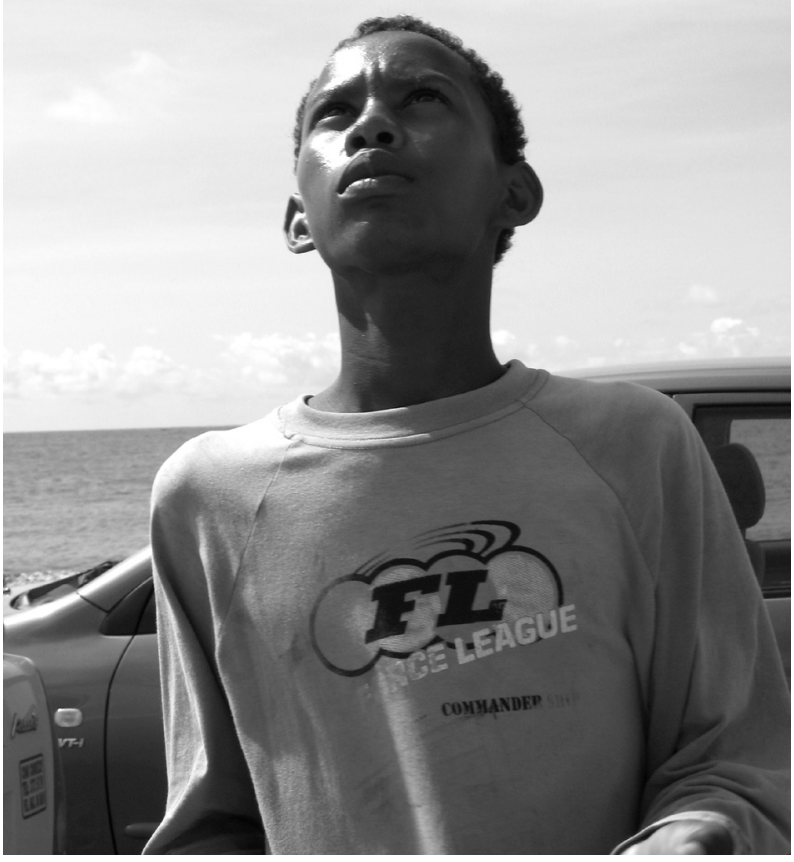


acciones sociales, a fin de que la gestión de los entes públicos y privados, a pesar de que parte de éste, se centre más en promover la movilización de la sociedad civil, a fin de que se trabaje en el sentido de fomentar verdaderamente, sujetos constructores de su propio desarrollo.

\section{BIBLIOGRAFÍA}

Agencia Presidencial para la Acción Social y la Cooperación Internacional www. red.gov.co

ANDER EGG, Ezequiel. (1981). Diccionario especializado de Trabajo Social. Lumen Humanitas. Alicante.

MARTURET, Hernán Javier. (2002). Visiones abiertas y cerradas de la modernidad. Una lectura de Pilles Lipovetky y Alain Tourraine. Universidad libros. Buenos Aires.

Microsoft student 2206. Microsoft corporation 2005.

http://www.un.org/spanish/mileniumgoals/-33k

http://es.wikipedia.org/wiki\%c3\%89mile_Durkheim.

\section{BIOGRAFIA}

\section{MARY BERRIO BERRIO}

Estudiante de X semestre del Programa de Trabajo Social de la Universidad de Cartagena, año 2008

\section{INDIRA JOLY GELIZ}

Estudiante de X semestre del Programa de Trabajo Social de la Universidad de Cartagena, año 2008. 